\title{
Tantalum-based electrocatalysts prepared by a microemulsion method for the oxygen reduction and evolution reactions
}

\author{
J.C. Ruiz-Cornejo ${ }^{1}$, D. Sebastián ${ }^{1,}{ }^{*}$, M.V. Martínez-Huerta ${ }^{2}$, M.J. Lázaro ${ }^{1}$ \\ ${ }^{1}$ Instituto de Carboquímica, CSIC. Miguel Luesma Castán 4, 50018, Zaragoza, Spain. \\ ${ }^{2}$ Instituto de Catálisis y Petroleoquímica, CSIC. Marie Curie 2, 28049, Madrid, Spain. \\ * Corresponding author: dsebastian@icb.csic.es
}

\begin{abstract}
Bifunctional catalysts for oxygen electrodes, active for both the oxygen reduction and evolution reactions (ORR, OER), are highly desirable for the development of electrochemical energy conversion devices. In this work, carbon-supported tantalum based catalysts were synthesized by a microemulsion procedure from tantalum ethoxide through a fast hydrolysis reaction followed by heat treatment. The nature and composition of the different tantalates and oxides (general formula $\mathrm{Na}_{\mathrm{a}} \mathrm{Ta}_{\mathrm{b}} \mathrm{O}_{\mathrm{c}}$, with $\mathrm{a} / \mathrm{b}=0-1$ and $\mathrm{c} / \mathrm{b}=2.5-3$ ) relied on the concentration of ethanol as well as on the annealing temperature, with $\mathrm{Na}_{2} \mathrm{Ta}_{8} \mathrm{O}_{21}$ as predominant crystal phase in all cases. High annealing temperatures resulted in a certain degree of oxygen substoichiometry, which creates defects responsible of electrocatalytic activity. The electrochemical response for the oxygen reduction and the oxygen evolution reactions in alkaline electrolyte $(0.1 \mathrm{M} \mathrm{NaOH})$ was evaluated for the first time in this type of materials. The presence of $\mathrm{Na}_{2} \mathrm{Ta}_{8} \mathrm{O}_{21}$ phase over other oxides/tantalates, a high crystallinity of such Ta-phase, and the oxygen substoichiometry are the three parameters playing a relevant role to favor ORR and OER electro-activity. The best formulations were found in a trade-off situation using $3 \%$ ethanol and annealing at $900^{\circ} \mathrm{C}$.
\end{abstract}

Keywords: tantalum; sodium tantalate; oxygen reduction reaction; oxygen evolution reaction; bifunctional electrode. 


\section{Introduction}

The design of electrocatalytic materials with high efficiency for two crucial reactions in the bifunctional oxygen electrodes, namely the oxygen reduction reaction (ORR) and oxygen evolution reaction (OER), is essential for the development of new emerging electrochemical energy storage and conversion devices, including unitized regenerative fuel cells and rechargeable metal-air batteries among others [1-3] [4-6].

Although some combinations of noble metals such as Pt and metal oxides $\left(\mathrm{RuO}_{2}, \mathrm{IrO}_{2}\right)$ possess excellent activity as bifunctional electrocatalyts, their high cost and instability hinder large-scale applications [7]. In the past few years, most research studies have focused on non-precious metal electrocatalysts using alkaline electrolytes [8], including transition metal-based and heteroatom doped carbonaceous materials [9-14].

Tantalum-based materials have demonstrated to be active and robust electrocatalysts for oxygen reduction reaction (ORR) in acidic environment due to its high corrosion resistance [15-21]. The presence of oxygen vacancies in the oxides can play a crucial role in the ORR because they may enhance the electrical conductivity as well as serve as the active sites for $\mathrm{O}_{2}$ adsorption $[22,23]$ $[24,25]$.

Awaludin et al. [21] established that the high activity in hydrogen evolution reaction (HER) and oxygen reduction reaction (ORR) of their tantalum-based electrode was due to the formation of suboxide species, i.e. $\mathrm{Ta}^{4+}$, obtained by an electrochemically reductive treatment. Furthermore, the formation of complex oxides such as $\mathrm{Na}_{2} \mathrm{Ta}_{8} \mathrm{O}_{21-\mathrm{x}}$ can change the oxidation state of metal species to form active and stable catalytic sites able to adsorb oxygen molecules and to introduce electronic levels in the energy gap [15].

The aim of this work is to synthetize tantalum-based materials as bifunctional electrocatalysts for the ORR and the OER in alkaline medium. It is known the difficulty to control group IV or V oxides on the nanoscale using conventional methods such as impregnation [26]. Primary 
nanoparticles of oxide catalysts can be prepared, but these fine particles easily aggregate to form larger secondary particles during high-temperature preparation [16]. For this reason, electrodeposition methods have been commonly used to control the size and distribution of metal particles of Ta-based materials on conductive substrates [17, 19, 27, 28].

In this work, we analyze the characteristics of a procedure for fabrication of carbon-supported tantalum-based electrocatalysts by a microemulsion method [29]. The effects of the amount of ethanol and calcination temperature on the structure, as well as ORR and OER activities in alkaline medium have been investigated. To the best of our knowledge, this is the first attempt to apply tantalum-based materials as ORR and OER electrocatalysts in alkaline environment.

\section{Experimental section}

\subsection{Synthesis of tantalum-based electrocalysts.}

Tantalum oxides (including sodium tantalates) supported on a commercial carbon black support were prepared by a microemulsion procedure [29]. The microemulsion (ME) was prepared by adding $0.25 \mathrm{ml}$ of $75 \mathrm{mM} \mathrm{NaOH}$ (Alfa Aesar 99.99\%) aqueous solution to an oil phase composed of $2.3 \mathrm{~g}$ of a surfactant (Igepal CO-520, Aldrich), $20 \mathrm{ml}$ of n-heptane (Honeywell) and 6 different amounts of ethanol (Labkem 99.5\%) from 0 to $1.5 \mathrm{ml}$. Afterwards, $0.05 \mathrm{ml}$ of tantalum (V) ethoxide (Aldrich 99.98\%) (0.3 mmol) was added to the $\mathrm{ME}$ at room temperature under continuous stirring. The mixture reacts producing tantalum oxide-based nanoparticles within 5 min [29]. Subsequently, $312 \mathrm{mg}$ of the carbon support (commercial carbon black Vulcan XC72R) is added to the suspension and kept under stirring overnight. The material is washed with ethanol and then with water, followed by drying at $60{ }^{\circ} \mathrm{C}$ overnight. A final step consists of a heat treatment in inert atmosphere $\left(\mathrm{N}_{2}\right)$ during $90 \mathrm{~min}$. Temperatures from $700{ }^{\circ} \mathrm{C}$ to $1000{ }^{\circ} \mathrm{C}$ were studied. Then the material is washed with water and dried at $60{ }^{\circ} \mathrm{C}$ overnight. The catalysts are labeled as $\mathrm{TaO}_{\mathrm{x}} / \mathrm{C}$ followed by the weight percentage of ethanol in the $\mathrm{ME}(0,1,2,3,4$ and 6 
wt.\%), and the annealing temperature $\left(700,800,900\right.$ and $\left.1000^{\circ} \mathrm{C}\right)$. Table 1 shows all catalysts prepared in this work.

\subsection{Solid-state characterization}

Transmission electron microscopy (TEM) analyses were made with a Tecnai F30 (FEI) microscope. For the analysis, the catalysts were dispersed in ethanol and then some drops of the dispersion were deposited on a carbon film coated $\mathrm{Cu}$ grid. The particle size distribution of each catalyst was obtained using ImageJ software on TEM images and statistic tools of OriginLab software from the measurement of at least 50 metallic nanoparticles. The X-ray diffraction (XRD) analyses were made with a Bruker D8 Advance diffractometer with $\mathrm{CuK} \alpha$ of $1600 \mathrm{~W}$. The total metal oxide content in the catalysts was obtained by thermogravimetric analysis in air atmosphere with a Libra F1 Netzch thermobalance. Energy-dispersive X-ray spectroscopy (EDX) was made with a Tecnai F30 (FEI) microscope in mode Scanning TEM-EDX at $300 \mathrm{kV}$.

\subsection{Electrochemical characterization}

Electrochemical studies were carried out in a three-electrode cell at room temperature controlled by an Autolab PGSTAT302 potentiostat-galvanostat, using 0.1M NaOH (Alfa Aesar, 99.99\%) aqueous solution as electrolyte with ultrapure water (MilliQ, Millipore). A reversible hydrogen electrode (RHE) in the supporting electrode was used as reference and a glassy carbon rod as counter electrode. The catalysts were deposited on a rotatory disc electrode (RDE), with a disk of glassy carbon (5 mm diameter) with a catalyst loading on the disk of $500 \mu \mathrm{g} \mathrm{cm}^{-2}$. The catalytic layer was obtained preparing $1 \mathrm{mg} \mathrm{ml}^{-1}$ ink by sonicating the catalyst in isopropanol/water (50:50) and Nafion ${ }^{\circledR}$ (5\%, Sigma Aldrich) as binder (30 wt\%). Several drops of the ink were deposited onto the glassy carbon to obtain the required mass loading.

Endurance tests were done in order to evaluate the electrode behavior with time under both ORR and OER conditions. The tests consisted of chronopotentiometric curves in which consecutive and alternative cycles of $180 \mathrm{~s}$ each were applied, with a current density of $1 \mathrm{~mA} \mathrm{~cm}{ }^{-2}$ for the OER and $-1 \mathrm{~mA} \mathrm{~cm}^{-2}$ for the ORR. A cut-off potential of $1.9 \mathrm{~V}$ vs. RHE was stablished for the 
OER and of $0.2 \mathrm{~V}$ vs. RHE for the ORR. The tests were made on a RDE with same characteristics as the previous description and at a rotation rate of $400 \mathrm{rpm}$.

\section{Results and discussion}

\subsection{Physico-chemical characterization}

Transmission electron microscopy (TEM) images for carbon-supported Ta-based catalysts, synthesized with $2 \%$ and $3 \%$ of ethanol and treated at $700,800,900$ and $1000^{\circ} \mathrm{C}$, are shown in Figure 1. In all micrographs the carbon phase presents a lighter grey aspect while the metal-based nanoparticulated phase is clearly differentiated by a darker contrast. The metal oxides are not evenly distributed on the surface of carbon, but randomly mixed with the support.

(a)

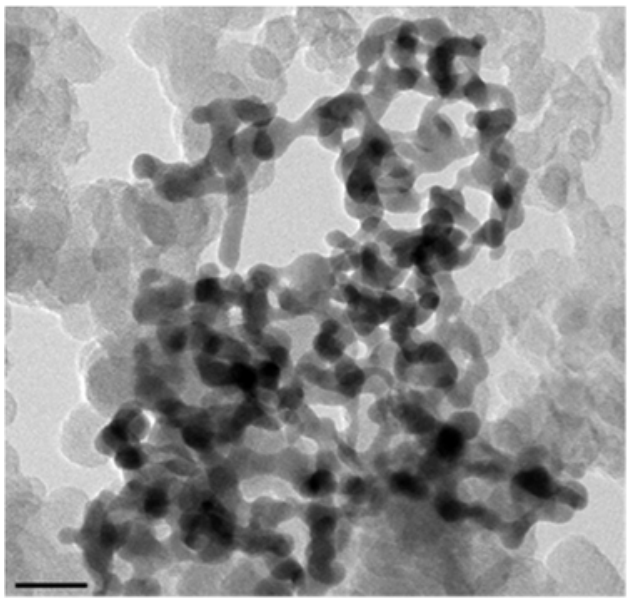

(b)

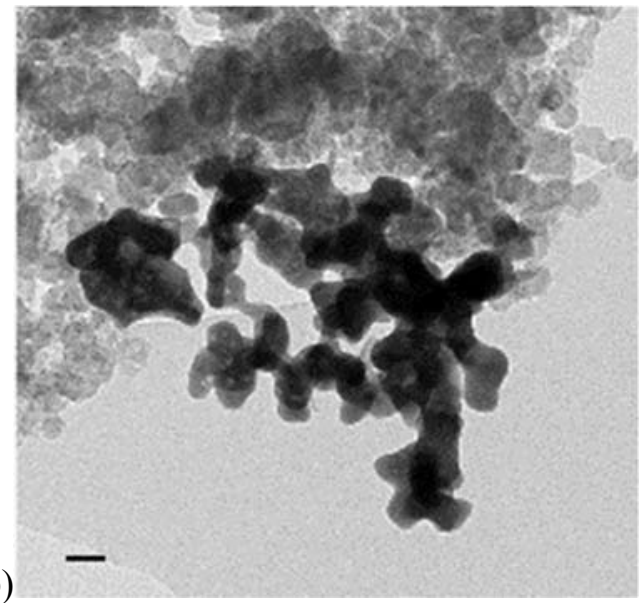

(d)

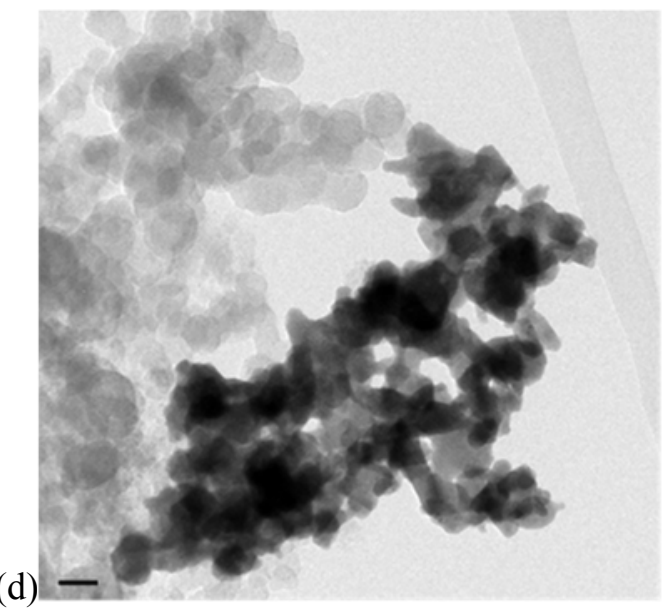



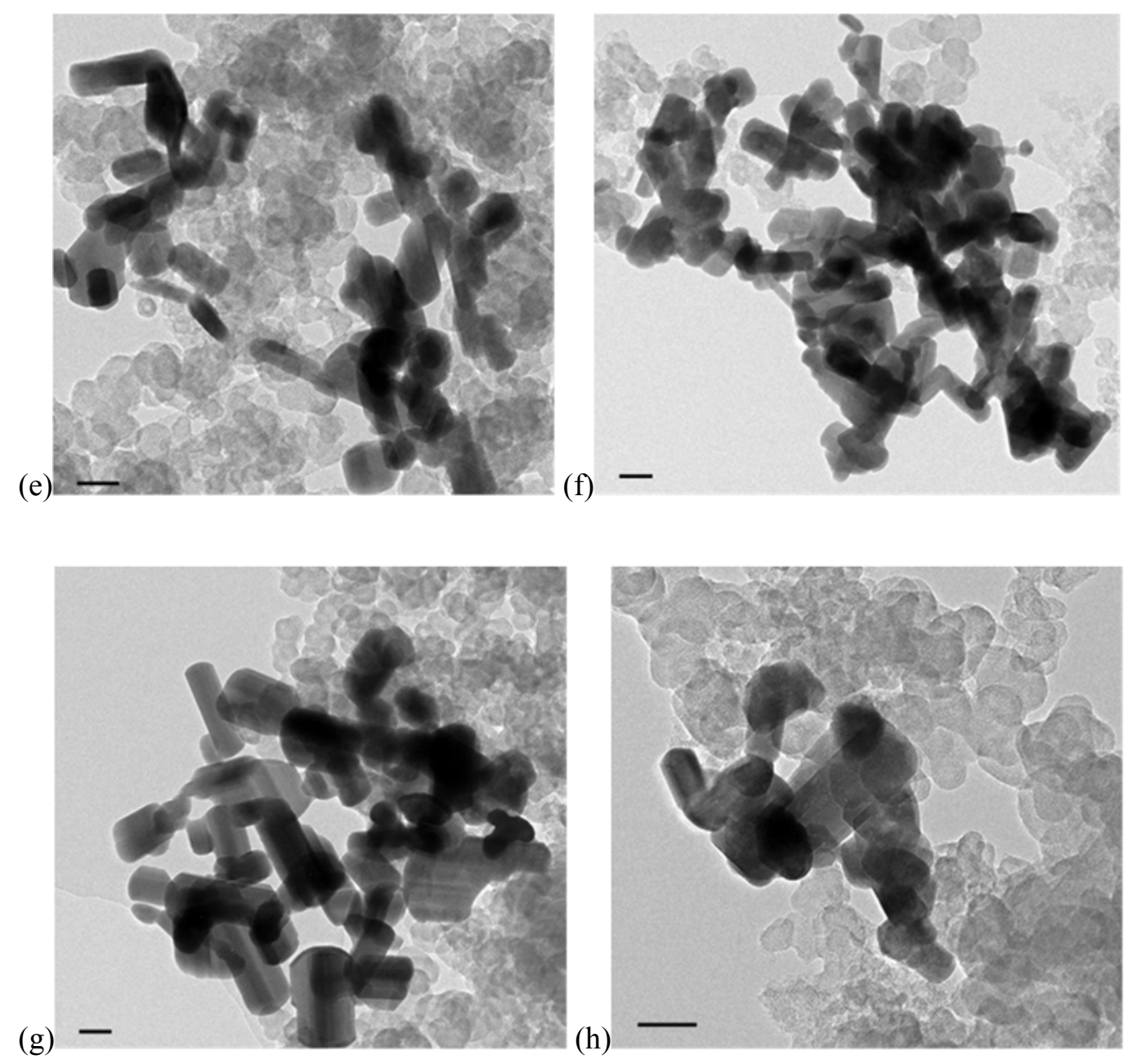

Figure 1. TEM micrographs for catalysts treated at different temperatures: a-b) $700^{\circ} \mathrm{C}$; c-d) $800^{\circ} \mathrm{C}$; e-f) $900^{\circ} \mathrm{C}$; and g-h) $1000^{\circ} \mathrm{C}$. Catalysts synthesized with $2 \%$ of ethanol are shown at the left column (a, c, e, g) and those with $3 \%$ of ethanol at the right one (b, d, f, h). Scale bar: $50 \mathrm{~nm}$.

The influence of the annealing temperature is depicted by comparing the images in Figure 1. The morphology of the metal oxide particles changes from a rounded shape $\left(700^{\circ} \mathrm{C}\right)$ towards a prismatic and more ordered arrangement $\left(1000^{\circ} \mathrm{C}\right)$ as the treatment temperature increases. At $700^{\circ} \mathrm{C}$ and $2 \%$ ethanol (Figure 1a), particles present a chain-like aspect formed by various series of globular particles of about $15-25 \mathrm{~nm}$ linked with each other. This is also the apparent morphology at the same temperature but prepared with 3\% ethanol in the ME, with larger particles of about 35-45 nm (Figure 1b). This kind of morphology is derived from the use of micelles in the microemulsion. A water in oil micromulsion, like the one used in this work, allows the limitation of particle growing in the core of the nanosized droplets. Depending on the ME 
composition, the nanodrops can coalesce during the reaction of Ta precursor, resulting in the chain-like aspect.

(a)

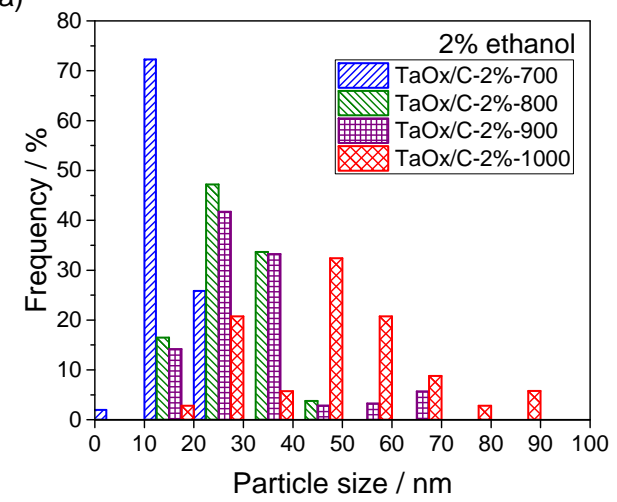

(b)

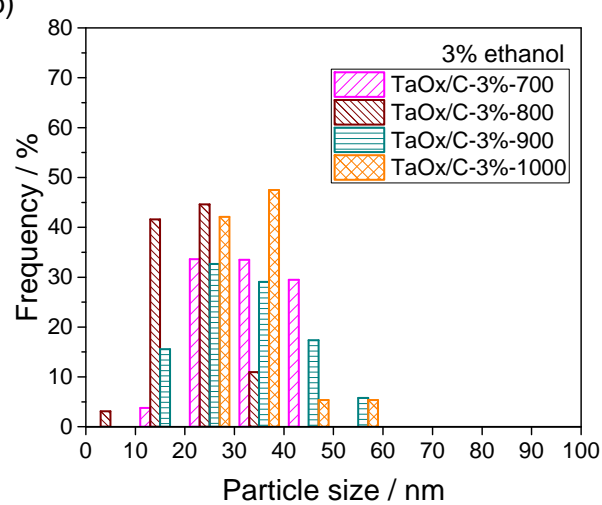

Figure 2. Particle size distribution for tantalum oxide-based nanoparticles from TEM images. (a) $2 \%$ ethanol. (b) $3 \%$ ethanol.

Particle size distributions (PSDs) of Figure 2 been obtained from TEM images. The PSD for the catalyst series synthesized with $2 \%$ of ethanol (Figure $2 a$ ) shows an increase of particle size when increasing the annealing temperature. At $700{ }^{\circ} \mathrm{C}$, more than $70 \%$ particles present sizes between 10 and $20 \mathrm{~nm}$, with a narrow distribution. The increase of annealing temperature results in an increase of average particle size and a widening of the distribution caused by the sintering of particles. In the catalyst $\mathrm{TaOx} / \mathrm{C}-2 \%-1000$ a bimodal distribution is observed. The effect of the treating temperature on the PSD is not so clear for the catalyst series synthesized with $3 \%$ of ethanol (Figure 2b). Relatively broad distributions were observed regardless the annealing temperature in this case.

At temperatures higher than $800^{\circ} \mathrm{C}$, the morphology of the particles is mostly elongated, i.e. with a preferential growth direction, and characterized by a higher crystallinity, as envisaged from the presence of planes in comparison to the catalysts obtained at the lowest temperature $\left(700^{\circ} \mathrm{C}\right)$ with amorphous aspect. Particles are sized in the range 40-80 nm (shorter dimension) and 80-150 nm (longer dimension) when treated at $1000^{\circ} \mathrm{C}$, indicating a significant growth of the oxides with temperature. 

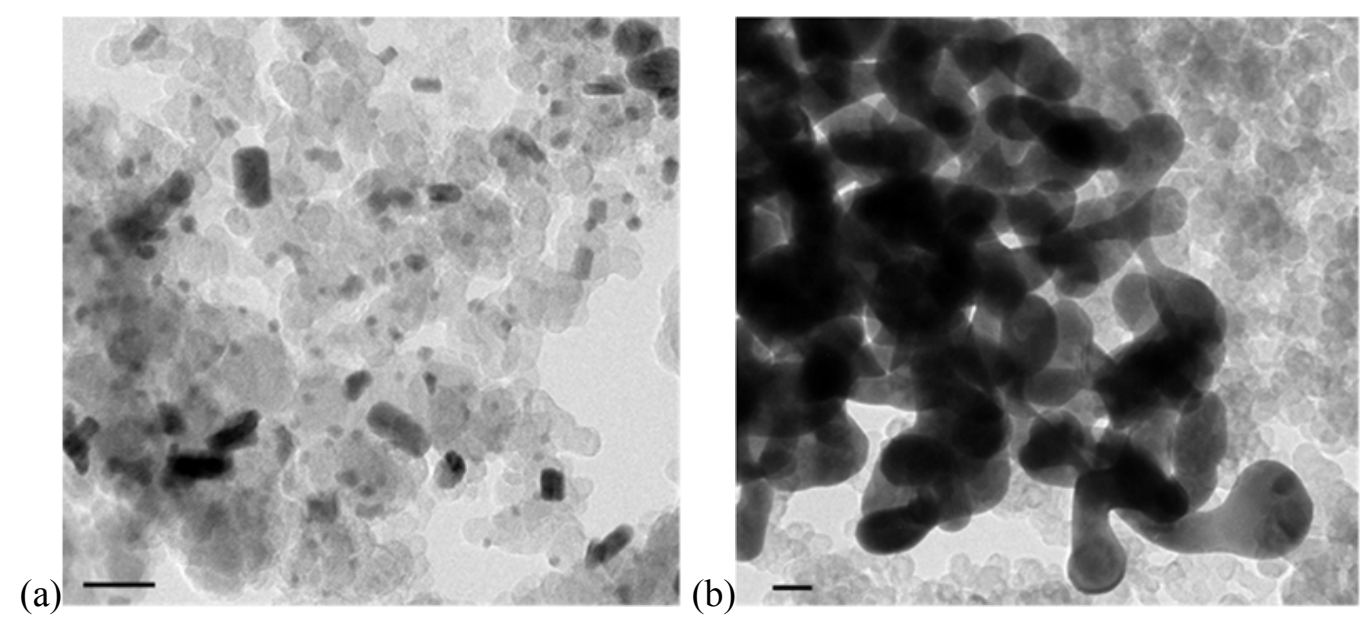

Figure 3. TEM micrographs for catalysts synthesized (a) without ethanol; (b) with $6 \%$ ethanol. Thermal annealing at $900^{\circ} \mathrm{C}$. Scale bar: $50 \mathrm{~nm}$.

The effect of ethanol concentration is also very relevant to the morphology and size of the Tabased particles. Figure 2 depicts TEM micrographs for catalysts treated at $900{ }^{\circ} \mathrm{C}$ both without ethanol (Figure 3a) and with $6 \%$ ethanol (Figure 3b). It is observed a dramatic effect of ethanol concentration on the particle size for Ta-based phase. Without ethanol, a bimodal distribution of sizes is obtained, mostly populated by small spherical particles with average diameter of $9.5 \mathrm{~nm}$, and a few larger particles with elongated shape and dimensions between 20 and $40 \mathrm{~nm}$. Whereas, the utilization of $6 \%$ ethanol results in the agglomeration of Ta-based particles, with rounded morphology and connected with each other. Intermediate concentrations of ethanol result in average diameters in between the latter two situations, as we can see in Figures 1(e) and 1(f), with samples treated at $900{ }^{\circ} \mathrm{C}$ with $2 \%$ and $3 \%$ ethanol, respectively.

The X-ray diffraction (XRD) patterns for the catalysts obtained using different amounts of ethanol during the synthesis is shown in Figure 4 for samples thermally treated at $900{ }^{\circ} \mathrm{C}$. Several species of tantalum oxide and sodium tantalates were identified. These are, in increasing order of relative oxygen-to-tantalum and sodium-to-tantalum contents: $\mathrm{Ta}_{2} \mathrm{O}_{5}$ (JCPDS \#25-0922, orthorhombic), $\mathrm{Na}_{2} \mathrm{Ta}_{8} \mathrm{O}_{21}$ (JCPDS \#28-1137), $\mathrm{Na}_{2} \mathrm{Ta}_{4} \mathrm{O}_{11}$ (JCPDS \#84-0810), and $\mathrm{NaTaO}_{3}$ (JCPDS \#74-2477). The Miller indexes for each of these reference patterns can be consulted in the Supplementary Information (Figures S1 to S4). The formation of the different oxides/tantalates results from the hydrolysis reaction of tantalum ethoxide with water (Eq. 1) in the presence of sodium hydroxide. Ethanol is obtained as a reaction product together with the metallic oxide phase. In the absence 
of sodium hydroxide, tantalum is deposited only as $\mathrm{Ta}_{2} \mathrm{O}_{5}$. Whereas, the presence of sodium cations in the solution gives place to the precipitation of sodium tantalates with different stoichiometries. Interestingly, the nature of the tantalate can be tuned with an appropriate selection of ethanol in the solution.

$\mathrm{b} / 2 \mathrm{Ta}_{2}\left(\mathrm{CH}_{3} \mathrm{CH}_{2} \mathrm{O}\right)_{10}+(\mathrm{c}-\mathrm{a}) \mathrm{H}_{2} \mathrm{O}+\mathrm{a} \mathrm{NaOH} \rightarrow \mathrm{Na}_{\mathrm{a}} \mathrm{Ta}_{\mathrm{b}} \mathrm{O}_{\mathrm{c}}+5 \mathrm{~b} \mathrm{CH}_{3} \mathrm{CH}_{2} \mathrm{OH}$

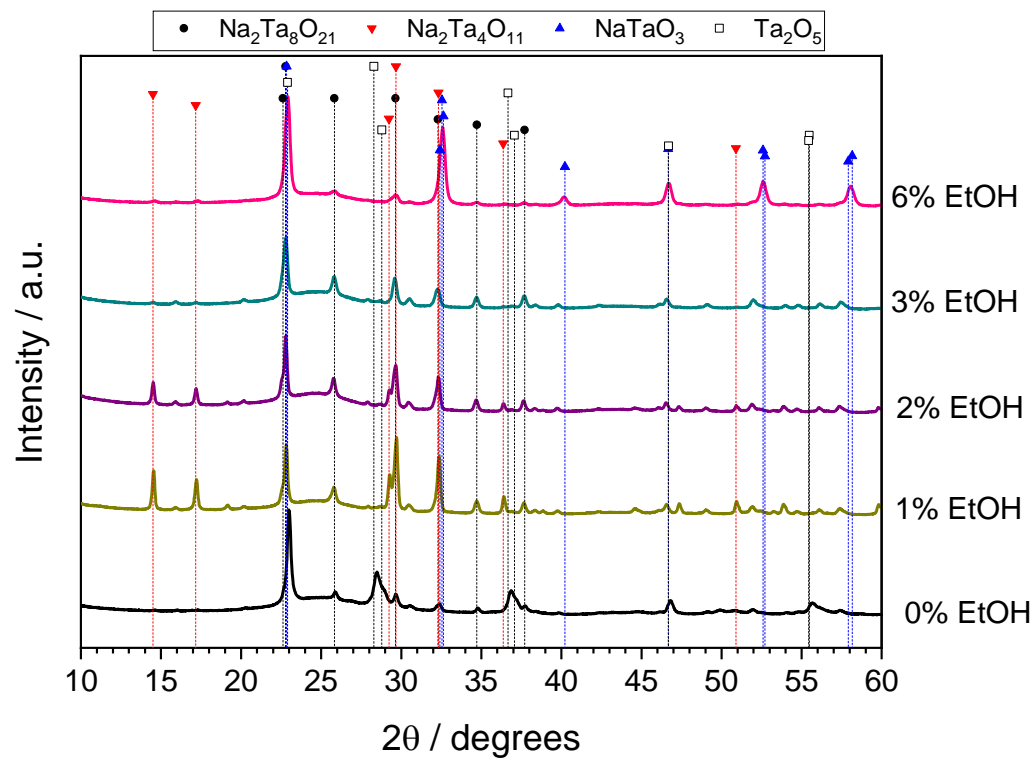

Figure 4. The effect of ethanol (EtOH) concentration on the crystallinity (XRD patterns) for catalysts annealed at $900^{\circ} \mathrm{C}$. Within the reference patterns (symbols), only the most intense reflections are included for the sake of clarity.

In the analysis of the nature of tantalates/oxides, some reflections are coincident in similar intervals of Bragg angles, like the one appearing at $2 \theta=22.6-22.9^{\circ}$, which can be related to planes ( $\left(\begin{array}{lll}0 & 0 & 1\end{array}\right)$ of $\mathrm{Ta}_{2} \mathrm{O}_{5}$, or $\left(\begin{array}{lll}1 & 1 & 0\end{array}\right)$ of $\mathrm{NaTaO}_{3}$, or $\left(\begin{array}{llll}3 & 3 & 0\end{array}\right) /\left(\begin{array}{lll}0 & 0 & 1\end{array}\right)$ of $\mathrm{Na}_{2} \mathrm{Ta}_{8} \mathrm{O}_{21}$; or the reflection appearing at $2 \theta=32.2-32.6^{\circ}$, which can be ascribed to planes $\left(\begin{array}{lll}0 & 1 & 1\end{array}\right) /\left(\begin{array}{lll}1 & 0 & 1\end{array}\right)$ of $\mathrm{NaTaO}_{3},\left(\begin{array}{lll}3 & 3 & 1\end{array}\right)$ of $\mathrm{Na}_{2} \mathrm{Ta}_{8} \mathrm{O}_{21}$ or (1 116$)$ of $\mathrm{Na}_{2} \mathrm{Ta}_{4} \mathrm{O}_{11}$. For the sake of clarity, the following discussion will focus on the intense reflections that can be ascribed to only one of the phases.

All materials exhibit the reflections attributed to the $\mathrm{Na}_{2} \mathrm{Ta}_{8} \mathrm{O}_{21}$ phase, as most clearly seen by the signals at $2 \theta=25.826^{\circ}$ and $34.715^{\circ}$, related to $\left(\begin{array}{lll}3 & 6 & 0\end{array}\right)$ and $\left(\begin{array}{lll}3 & 6 & 1\end{array}\right)$ planes of the orthorhombic structure of sodium tantalate. The catalyst prepared without ethanol presents also the reflections from orthorhombic $\mathrm{Ta}_{2} \mathrm{O}_{5}$, with peaks at $2 \theta=28.291^{\circ}, 28.795^{\circ}, 36.666^{\circ}$ and $37.073^{\circ}$ as the most 
differing ones compared to the other structures, related to (1 1110$),\left(\begin{array}{lll}2 & 0 & 0\end{array}\right),\left(\begin{array}{lll}1 & 11 & 1\end{array}\right)$ and $\left(\begin{array}{lll}2 & 0 & 1\end{array}\right)$ planes of $\mathrm{Ta}_{2} \mathrm{O}_{5}$.

The catalysts prepared with $1 \%$ and $2 \%$ ethanol exhibit similar profiles with each other, including $\mathrm{Na}_{2} \mathrm{Ta}_{8} \mathrm{O}_{21}$ and $\mathrm{Na}_{2} \mathrm{Ta}_{4} \mathrm{O}_{11}$ as main crystallographic phases, while $\mathrm{Ta}_{2} \mathrm{O}_{5}$ is no longer detected, differing from the sample prepared with $0 \%$ ethanol. Indeed, the different reflections that are more clearly visible are those appearing at $2 \theta=14.502^{\circ}$ and $17.173^{\circ}$ from $\mathrm{Na}_{2} \mathrm{Ta}_{4} \mathrm{O}_{11}\left(\begin{array}{lll}0 & 0 & 6\end{array}\right)$ and $\left(\begin{array}{ll}0 & 1\end{array}\right.$ 2) planes, respectively. The catalyst prepared with $3 \%$ ethanol exhibits mainly the reflections related to the phase $\mathrm{Na}_{2} \mathrm{Ta}_{8} \mathrm{O}_{21}$, with small contributions from $\mathrm{Na}_{2} \mathrm{Ta}_{4} \mathrm{O}_{11}$. Whereas, the catalyst prepared with $6 \%$ ethanol clearly shows reflections related to $\mathrm{NaTaO}_{3}$, together with the diffraction peaks of $\mathrm{Na}_{2} \mathrm{Ta}_{8} \mathrm{O}_{21}$.

All these results indicate that, the selection of ethanol concentration in the microemulsion synthesis for the hydrolysis of Ta ethoxide is relevant to favor the formation of certain Ta-based crystallographic species, all of them containing $\mathrm{Na}_{2} \mathrm{Ta}_{8} \mathrm{O}_{21}$, with variable contents of the other three tantalum species.

Figure 5 shows the influence of the annealing temperature on the XRD patterns for the catalysts prepared with $2 \%$ and $3 \%$ ethanol. It is clear that the treatment temperature also affects the chemical composition of the catalysts. The samples prepared with $2 \%$ and $3 \%$ ethanol contain both $\mathrm{Na}_{2} \mathrm{Ta}_{8} \mathrm{O}_{21}$ and $\mathrm{Na}_{2} \mathrm{Ta}_{4} \mathrm{O}_{11}$, but the relative content of these two species varies with the annealing treatment, as envisaged from the variation of the intensities of the corresponding reflections. The predominance of $\mathrm{Na}_{2} \mathrm{Ta}_{8} \mathrm{O}_{21}$ is favored by annealing at $800^{\circ} \mathrm{C}$ for the $2 \%$ series, and over $900^{\circ} \mathrm{C}$ for the $3 \%$ series. In any case, $700^{\circ} \mathrm{C}$ appears as not sufficient temperature to result in crystalline particles, in accordance with TEM observations of globular shaped particles. 
(a)

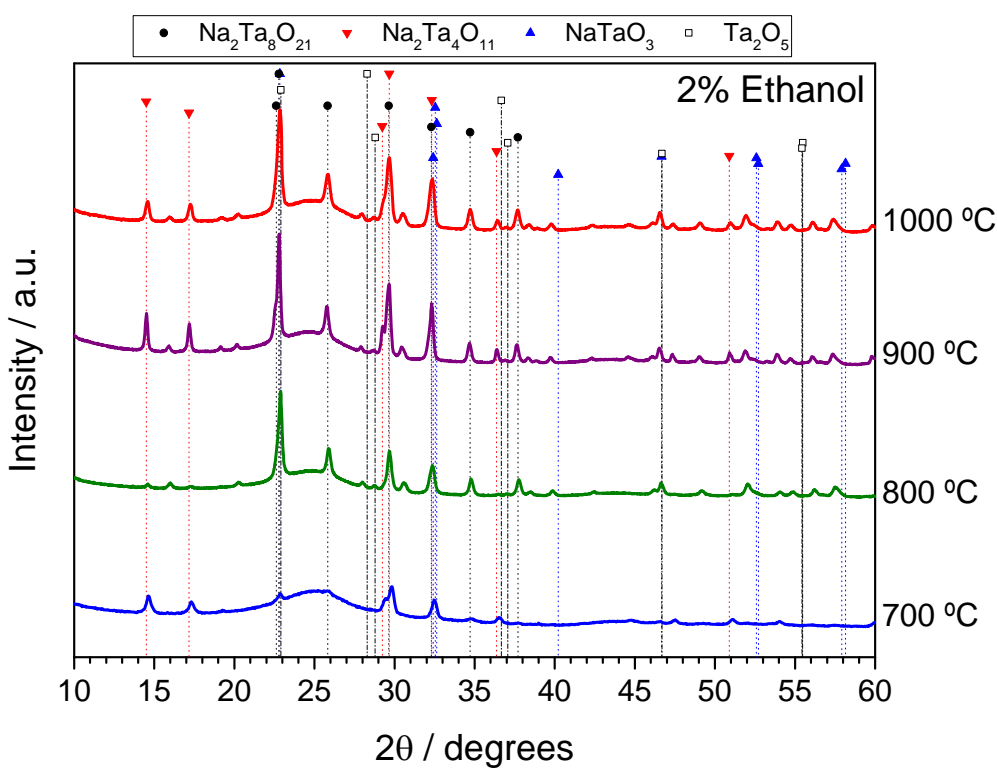

(b)

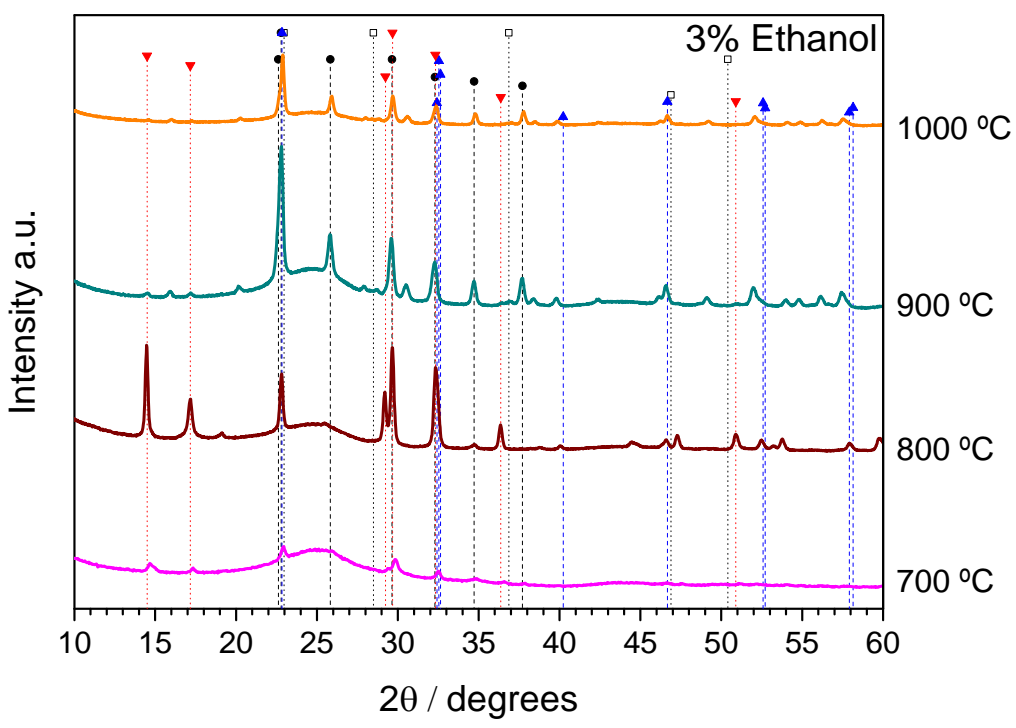

Figure 5. XRD patterns of the catalysts obtained at different temperatures synthesized with (a) $2 \%$ of ethanol and (b) $3 \%$ of ethanol.

Table 1 summarizes the crystalline species and the crystallite size of the catalysts according to the amount of ethanol used during the synthesis and the treatment temperature. The main crystals obtained for almost any synthesis condition are $\mathrm{Na}_{2} \mathrm{Ta}_{8} \mathrm{O}_{21}$ and $\mathrm{Na}_{2} \mathrm{Ta}_{4} \mathrm{O}_{11}$. In general terms, the average crystallite size increases with the annealing temperature.

Table 1. Crystallite size (nm) for catalysts from XRD analyses. TaOx/C-X-Y (X: percentage of ethanol used in the synthesis; $\mathrm{Y}=$ annealing temperature in $\left.{ }^{\circ} \mathrm{C}\right)$.

\begin{tabular}{|l|l|l|l|l|}
\hline & \multicolumn{4}{|c|}{ Crystallite size $(\mathrm{nm})$} \\
\hline Catalyst & $\mathrm{Na}_{2} \mathrm{Ta}_{8} \mathrm{O}_{21}$ & $\mathrm{Na}_{2} \mathrm{Ta}_{4} \mathrm{O}_{11}$ & $\mathrm{NaTaO}_{3}$ & $\mathrm{Ta}_{2} \mathrm{O}_{5}$ \\
\hline
\end{tabular}




\begin{tabular}{|l|c|c|c|c|}
\hline TaOx/C-0\%-900 & 35.3 & - & - & 21.3 \\
\hline TaOx/C-1\%-900 & 45.3 & 57.9 & - & - \\
\hline TaOx/C-2\%-700 & 16 & 33 & - & - \\
\hline TaOx/C-2\%-800 & 37.1 & 33 & - & - \\
\hline TaOx/C-2\%-900 & 46.4 & 52 & - & - \\
\hline TaOx/C-2\%-1000 & 46.8 & 60.3 & - & - \\
\hline TaOx/C-3\%-700 & 21 & 34 & - & - \\
\hline TaOx/C-3\%-800 & - & 57 & - & - \\
\hline TaOx/C-3\%-900 & 33.9 & 42 & - & - \\
\hline TaOx/C-3\%-1000 & 43.9 & 34 & - & - \\
\hline TaOx/C-4\%-900 & 25.6 & 52.7 & - & - \\
\hline TaOx/C-6\%-900 & 18 & 31 & 34 & - \\
\hline \multicolumn{7}{|l}{} \\
\hline
\end{tabular}

EDX analysis of the metal oxide nanoparticles in STEM mode was used to determine the composition of the tantalates, minimizing the occurrence of carbon and oxygen signals from the carbonaceous support. The calculated ratios of oxygen and sodium with respect to tantalum are summarized in Table 2, together with those corresponding to the tantalum species identified in XRD analyses. The ratio between sodium and tantalum was found between 0.05 and 0.26 , indicating stoichiometries between $\mathrm{Na}_{2} \mathrm{Ta}_{8} \mathrm{O}_{21}$ and $\mathrm{Ta}_{2} \mathrm{O}_{5}$. Whereas, the $\mathrm{O} / \mathrm{Ta}$ ratio is close to stoichiometric $\mathrm{Ta}_{2} \mathrm{O}_{5}$ for three of the samples and much lower $(0.75-1.28)$ especially for samples treated at high temperature and prepared with 3\% ethanol. According to the literature, oxygen vacancies in the oxides of metals from groups IV and V of the periodic table are responsible of oxygen adsorption and electrocatalytic activity [30].

Table 2. Atomic ratio of oxygen/tantalum and sodium/tantalum obtained by EDX.

\begin{tabular}{|c|c|c|}
\hline & $\mathrm{O} / \mathrm{Ta}$ & $\mathrm{Na} / \mathrm{Ta}$ \\
\hline $\mathrm{TaOx} / \mathrm{C}-2 \%-700$ & 2.46 & 0.09 \\
\hline $\mathrm{TaO} / \mathrm{C}-2 \%-800$ & 4.49 & 0.26 \\
\hline TaOx/C -2\%-900 & 2.54 & 0.15 \\
\hline TaOx/C -2\%-1000 & 0.75 & 0.12 \\
\hline TaOx/C -3\%-700 & 2.59 & 0.10 \\
\hline $\mathrm{TaOx} / \mathrm{C}-3 \%-800$ & 1.28 & 0.11 \\
\hline $\mathrm{TaOx/C} \mathrm{-3 \% -900}$ & 1.12 & 0.07 \\
\hline TaOx/C -3\%-1000 & 1.24 & 0.04 \\
\hline TaOx/C -4\%-900 & 0.87 & 0.27 \\
\hline $\mathrm{Ta}_{2} \mathrm{O}_{5}$ & 2.5 & 0 \\
\hline $\mathrm{Na}_{2} \mathrm{Ta}_{8} \mathrm{O}_{21}$ & 2.625 & 0.25 \\
\hline $\mathrm{Na}_{2} \mathrm{Ta}_{4} \mathrm{O}_{11}$ & 2.75 & 0.5 \\
\hline $\mathrm{NaTaO}_{3}$ & 3 & 1 \\
\hline
\end{tabular}




\subsection{Electrochemical characterization}

The tantalate-based catalysts were studied for the ORR and the OER in a three-electrode half-cell configuration by using a rotating disc electrode (RDE). The electrolyte was in all studies $0.1 \mathrm{M}$ $\mathrm{NaOH}$ aqueous solution, saturated with $\mathrm{O}_{2}$ for ORR tests, and the experiments were carried out at room temperature.

\subsubsection{ORR activities of Ta-based catalysts synthesized with different ethanol concentrations}

The electrochemical activity for the catalysts treated at $900{ }^{\circ} \mathrm{C}$ with different ethanol concentrations $(0,1,2,3,4$ and $6 \%)$ towards the ORR is shown in Figure 6. The curves present the typical sigmoidal wave form for the oxygen electroreduction, with an onset potential of 0.70 $0.72 \mathrm{~V}$ vs. RHE (at $-0.1 \mathrm{~mA} \mathrm{~cm}$ ) and approaching a limiting current with the potential scan towards more negative values ascribed to oxygen diffusion limitation.

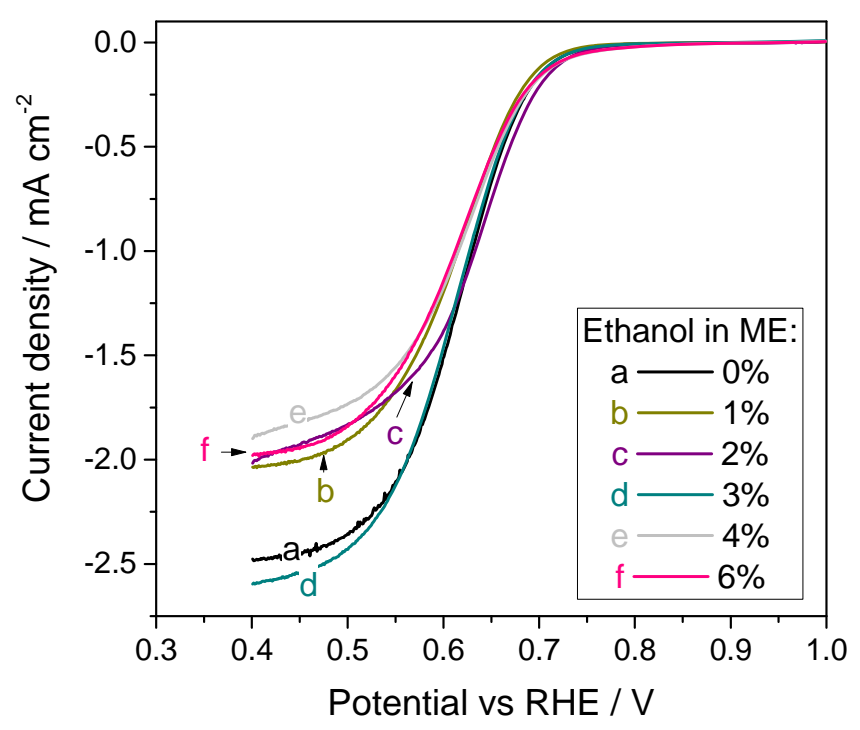

Figure 6. Effect of the amount of ethanol on the ORR polarization curves catalyst with the same annealing treatment $\left(900^{\circ} \mathrm{C}\right)$. Linear sweep voltammetry at $5 \mathrm{mV} \mathrm{s}^{-1}, 1600 \mathrm{rpm}, 0.1 \mathrm{M} \mathrm{NaOH}, 45 \mu \mathrm{g} \mathrm{cm}^{-2}$ of Ta.

The activity of these catalysts is lower if compared to other bifunctional catalysts published in the literature [9]. Only slight differences in terms of ORR activity were found by varying the amount of ethanol in the preparation of catalysts. Table 3 summarizes some ORR parameters of interest, including the kinetic current density $\left(j_{k, O R R}\right)$ at $0.65 \mathrm{~V}$ vs. RHE, the Tafel slope and the exchange 
current density $\left(j_{0, O R R}\right)$. Kinetic current densities were calculated considering the contribution of the diffusion limiting current density $\left(j_{d}\right)$ to the measured current $\left(j^{-1}=j_{k}^{-1}+j_{d}^{-1}\right)$. The capacitance for each catalyst in the deaerated supporting electrolyte was also determined from cyclic voltammograms (see Supplementary Information, Figures S5 to S7 and Table S1). The most active catalysts in terms of kinetic current density were those prepared with intermediate amounts of ethanol (2-3\%), characterized by intermediate nanoparticle size and the absence of $\mathrm{Ta}_{2} \mathrm{O}_{5}$ and $\mathrm{NaTaO}_{3}$ species according to XRD results. In general terms, both the Tafel slope and the exchange current density increase with the concentration of ethanol. According to the recent literature, Tafel slopes close to $60 \mathrm{mV} \mathrm{dec}^{-1}$ denote that the hydrolysis of adsorbed oxygen is the rate determining step for the associative mechanism of ORR in alkaline medium, whereas values closer to $120 \mathrm{mV}$ $\operatorname{dec}^{-1}$ might indicate that the first electron transference to adsorbed oxygen contributes also to the overall reaction rate [31]. Although catalysts prepared with $4 \%$ and $6 \%$ ethanol present much larger exchange current densities than the rest of the catalysts, the also larger Tafel slope of about $90 \mathrm{mV} \mathrm{dec}^{-1}$ leads to overall process with slower reaction compared to catalysts with Tafel slopes closer to $60 \mathrm{mV} \mathrm{dec}^{-1}$.

Table 3. Summary of ORR electrokinetic parameters for catalysts synthesized by varying the ethanol concentration. $\mathrm{j}_{\mathrm{k}, \mathrm{ORR}}$ is the kinetic part of the current density at $0.65 \mathrm{~V}$ vs. RHE, and $\mathrm{j}_{0, \mathrm{ORR}}$ is the exchange

\begin{tabular}{|l|c|c|c|}
\hline Electrocatalyst & $\begin{array}{c}\text { jk,ORR } \\
\left(\mathrm{mA} \mathrm{cm}^{-2}\right)\end{array}$ & $\begin{array}{c}\text { Tafel slope } \\
\left(\mathrm{mV} \mathrm{dec}^{-1}\right)\end{array}$ & $\begin{array}{c}\text { jo,ORR } \\
\left(\mathrm{mA} \mathrm{cm}^{-2}\right)\end{array}$ \\
\hline TaOx/C-0\%-900 & -0.89 & 66 & $1.1 \cdot 10^{-9}$ \\
\hline TaOx/C-1\%-900 & -0.71 & 65 & $1.1 \cdot 10^{-9}$ \\
\hline TaOx/C-2\%-900 & -1.24 & 72 & $3.3 \cdot 10^{-9}$ \\
\hline TaOx/C-3\%-900 & -1.24 & 70 & $6.7 \cdot 10^{-9}$ \\
\hline TaOx/C-4\%-900 & -0.83 & 94 & $2.4 \cdot 10^{-7}$ \\
\hline TaOx/C-6\%-900 & -0.78 & 90 & $3.2 \cdot 10^{-7}$ \\
\hline
\end{tabular}

The best ORR formulations within this set of electrocatalysts are the ones obtained with intermediate ethanol concentration (2-3\%), in which the formation of $\mathrm{Na}_{2} \mathrm{Ta}_{8} \mathrm{O}_{21}$ is favored over other Ta-based species. This might be responsible of sufficiently high exchange current density with a relatively low Tafel slope, resulting in the best kinetic current density among this set of catalysts. 


\subsubsection{OER activities of Ta-based catalysts synthesized with different ethanol concentrations}

The effect of ethanol concentration in the preparation of catalysts treated at $900{ }^{\circ} \mathrm{C}$ on their OER electrocatalytic activity is reported in Figure 7. The rotating speed for the electrode was maintained at $1600 \mathrm{rpm}$ to remove the produced $\mathrm{O}_{2}$ bubbles. There is not iR-corrected OER data. For this reaction, the differences encountered for catalysts prepared with different ethanol concentrations in OER is much more pronounced than those found in the case of ORR.

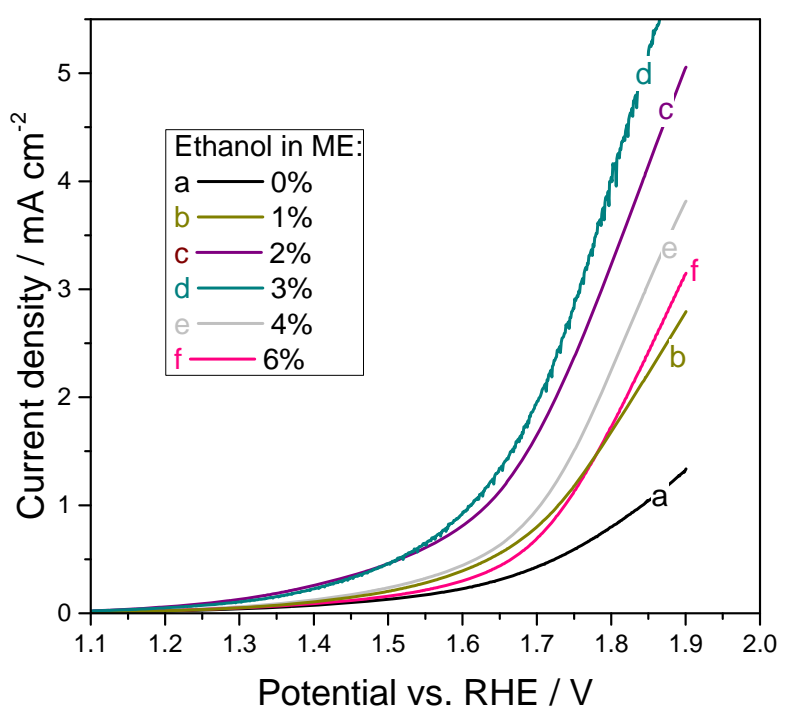

Figure 7. Effect of the amount of ethanol on the OER polarization curves catalyst with the same annealing treatment $\left(900^{\circ} \mathrm{C}\right)$. Linear sweep voltammetry at $5 \mathrm{mVs}^{-1}, 1600 \mathrm{rpm}, 0.1 \mathrm{M} \mathrm{NaOH}, 45 \mu \mathrm{g} \mathrm{cm}{ }^{-2}$ of Ta.

The OER electrochemical activity increases as the amount of ethanol used increases up to $3 \%$ (TaOx/C-3\%-900 catalyst), showing the highest activity of this series. However, higher ethanol concentration to $6 \%$ leads to a progressive decrease in activity, similar to TaOx/C-1\%-900 catalyst. The XRD analysis of TaOx/C-3\%-900 catalyst exhibited that $\mathrm{Na}_{2} \mathrm{Ta}_{8} \mathrm{O}_{21}$ was prevalent among the different crystalline species detected. This may indicate this phase is responsible for $\mathrm{OH}^{-}$oxidation towards oxygen, since the other catalysts in the series exhibited much lower OER activity. 
Table 4. Summary of OER electrokinetic parameters for catalysts synthesized by varying the ethanol concentration. $\mathrm{j}_{\mathrm{OER}}$ is the current density at $1.65 \mathrm{~V}$ vs. RHE, and $\mathrm{j}_{0, \mathrm{OER}}$ is the exchange current density (1.23 V vs. RHE).

\begin{tabular}{|l|c|c|c|}
\hline Electrocatalyst & $\begin{array}{c}\text { joen } \\
\left(\mathrm{mA} \mathrm{cm}^{-2}\right)\end{array}$ & $\begin{array}{c}\text { Tafel slope } \\
\left(\mathrm{mV} \mathrm{dec}^{-1}\right)\end{array}$ & $\begin{array}{c}\text { jo,OER } \\
\left(\mathrm{mA} \mathrm{cm}^{-2}\right)\end{array}$ \\
\hline TaOx/C-0\%-900 & 0.31 & 362 & $2.2 \cdot 10^{-2}$ \\
\hline TaOx/C-1\%-900 & 0.55 & 323 & $2.6 \cdot 10^{-2}$ \\
\hline TaOx/C-2\%-900 & 1.13 & 306 & $4.9 \cdot 10^{-2}$ \\
\hline TaOx/C-3\%-900 & 1.37 & 304 & $6.2 \cdot 10^{-2}$ \\
\hline TaOx/C-4\%-900 & 0.65 & 265 & $1.6 \cdot 10^{-2}$ \\
\hline TaOx/C-6\%-900 & 0.45 & 245 & $0.8 \cdot 10^{-2}$ \\
\hline
\end{tabular}

Table 4 summarizes some important parameters related to OER for this series of catalysts, including the current density at $1.65 \mathrm{~V}$ vs. RHE (jOER). The highest exchange current density $\left(j_{0, O E R}\right)$ was observed for the catalyst prepared with $3 \%$ ethanol, whereas the Tafel slope progressively decreases from 362 to $245 \mathrm{mV} \mathrm{dec}^{-1}$ when increasing the concentration of ethanol in the synthesis. A lower Tafel slope represents enhanced kinetics [32], but as the exchange current density also decreases in the same direction with ethanol concentration over $3 \%$, a compromise situation is found to maximize overall activity for the catalyst TaOx/C-3\%-900.

For the OER, a trade-off situation is found for intermediate ethanol concentration (3\%) to maximize the electro-catalytic activity, a similar behavior than in ORR investigation. This might be an indication of similar active sites acting for both reactions.

\subsubsection{ORR activities of Ta-based catalysts synthesized with different annealing temperatures}

The effect of the annealing temperature has been investigated on the catalysts synthesized with $2 \%$ (Figure 8 ) and 3\% (Figure 9) of ethanol. Table 5 summarizes the most important parameters regarding the ORR electro-activity. Within both series of catalysts, the increase of the annealing temperature improves the activity for the ORR as shown in the figures and also from the values of kinetic current density $\left(j_{k, O R R}\right)$. The largest difference was observed between catalysts treated at $700^{\circ} \mathrm{C}$, with low activity, and catalysts annealed at $800^{\circ} \mathrm{C}$ or higher, with more than $100 \mathrm{mV}$ improvement at the same current density. Additionally, the Tafel slope decreases also with annealing temperature approaching $60 \mathrm{mV} \mathrm{dec}^{-1}$, indicating faster kinetics, while the exchange current density $\left(j_{0, O R R}\right)$ exhibits the largest values for the samples treated at $800^{\circ} \mathrm{C}$ (Table 5). This 
observed pattern of activity with temperature occurs for samples prepared with both $2 \%$ and $3 \%$ ethanol concentration. Taking into account these two series of catalysts, the one exhibiting the largest activity in terms of kinetic current density is $\mathrm{TaOx} / \mathrm{C}-3 \%-1000$.

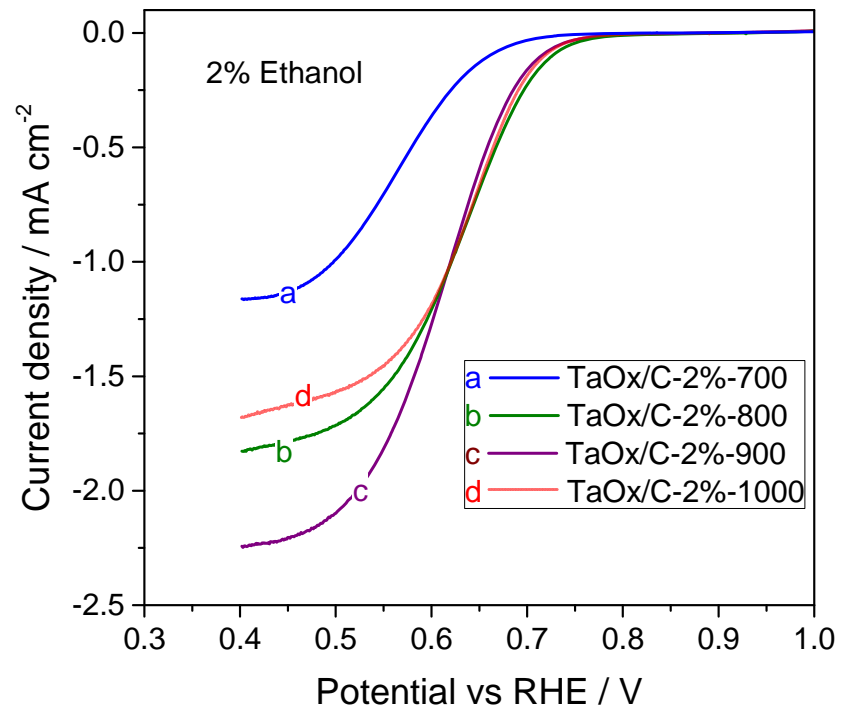

Figure 8. Effect of the temperature on ORR polarization curves for the catalysts synthesized with $2 \%$ of ethanol. Linear sweep voltammetry at $5 \mathrm{mV} \mathrm{s}^{-1}, 1600 \mathrm{rpm}, 0.1 \mathrm{M} \mathrm{NaOH}, 45 \mu \mathrm{g} \mathrm{cm}^{-2}$ of Ta.

As discussed above, the catalysts treated at $700^{\circ} \mathrm{C}$ showed small XRD reflections, indicating a small population of crystalline particles within the metal oxide phase. This is in agreement with TEM observation, where the catalysts treated at the lowest temperature exhibited globular and amorphous structure. Upon annealing at larger temperature, the catalysts become much more active. Therefore, it appears that the crystallinity of metal oxide particles is a key parameter to obtain ORR catalytic active sites. Much smaller differences were found for catalysts treated in the interval $800-1000^{\circ} \mathrm{C}$. 


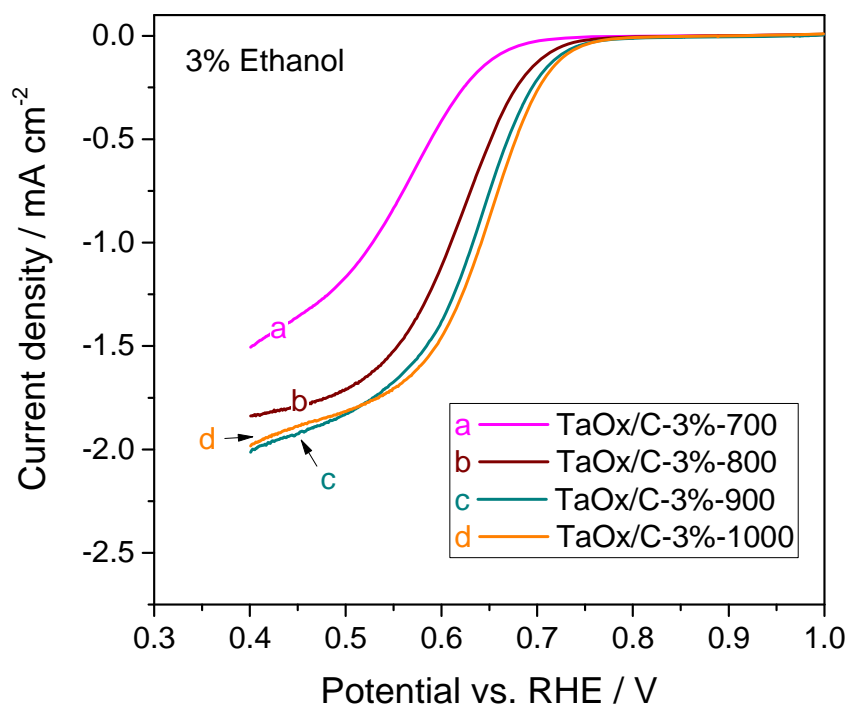

Figure 9. Effect of the temperature on ORR polarization curves for the catalysts synthesized with $3 \%$ of ethanol. Linear sweep voltammetry at $5 \mathrm{mV} \mathrm{s}^{-1}, 1600 \mathrm{rpm}, 0.1 \mathrm{M} \mathrm{NaOH}, 45 \mu \mathrm{g} \mathrm{cm}^{-2}$ of Ta.

Table 5. Summary of ORR electrokinetic parameters for catalysts synthesized by varying the annealing temperature. $\mathrm{j}_{\mathrm{k} \text {,ORR }}$ is the kinetic part of the current density at $0.65 \mathrm{~V}$ vs. RHE, and $\mathrm{j}_{0}, \mathrm{ORR}$ is the exchange current density (1.23 V vs. RHE).

\begin{tabular}{|l|c|c|c|}
\hline Electrocatalyst & $\begin{array}{c}\mathrm{j}_{\mathrm{k}, \mathrm{ORR}} \\
(\mathrm{mA} \mathrm{cm}-2)\end{array}$ & $\begin{array}{c}\text { Tafel slope } \\
\left(\mathrm{mV} \mathrm{dec}^{-1}\right)\end{array}$ & $\begin{array}{c}\mathrm{j}_{0, \mathrm{ORR}} \\
\left(\mathrm{mA} \mathrm{cm}-\mathrm{m}^{-2}\right)\end{array}$ \\
\hline TaOx/C-2\%-700 & -0.14 & 83 & $1.0 \cdot 10^{-8}$ \\
\hline TaOx/C-2\%-800 & -1.08 & 82 & $2.4 \cdot 10^{-8}$ \\
\hline TaOx/C-2\%-900 & -1.24 & 72 & $7.4 \cdot 10^{-9}$ \\
\hline TaOx/C-2\%-1000 & -1.15 & 66 & $1.7 \cdot 10^{-9}$ \\
\hline TaOx/C-3\%-700 & -0.14 & 81 & $8.9 \cdot 10^{-9}$ \\
\hline TaOx/C-3\%-800 & -0.72 & 76 & $9.9 \cdot 10^{-9}$ \\
\hline TaOx/C-3\%-900 & -1.24 & 72 & $6.6 \cdot 10^{-9}$ \\
\hline TaOx/C-3\%-1000 & -1.54 & 65 & $2.3 \cdot 10^{-9}$ \\
\hline
\end{tabular}

\subsubsection{OER activities of Ta-based catalysts synthesized with different annealing temperatures}

The effect of the annealing temperature on OER activity is shown in Figures 10 and 11. Similarly to ORR results, the catalysts treated at the lowest temperature $\left(700^{\circ} \mathrm{C}\right)$ show the lowest activity, with a significant increase upon annealing at higher temperature. The better OER catalytic activities for $\mathrm{TaOx} / \mathrm{C}-900$ catalysts were reflected by its more negative onset potentials and higher current densities than those of $\mathrm{TaOx} / \mathrm{C}-700, \mathrm{TaOx} / \mathrm{C}-800$ and $\mathrm{TaOx} / \mathrm{C}-1000$. 


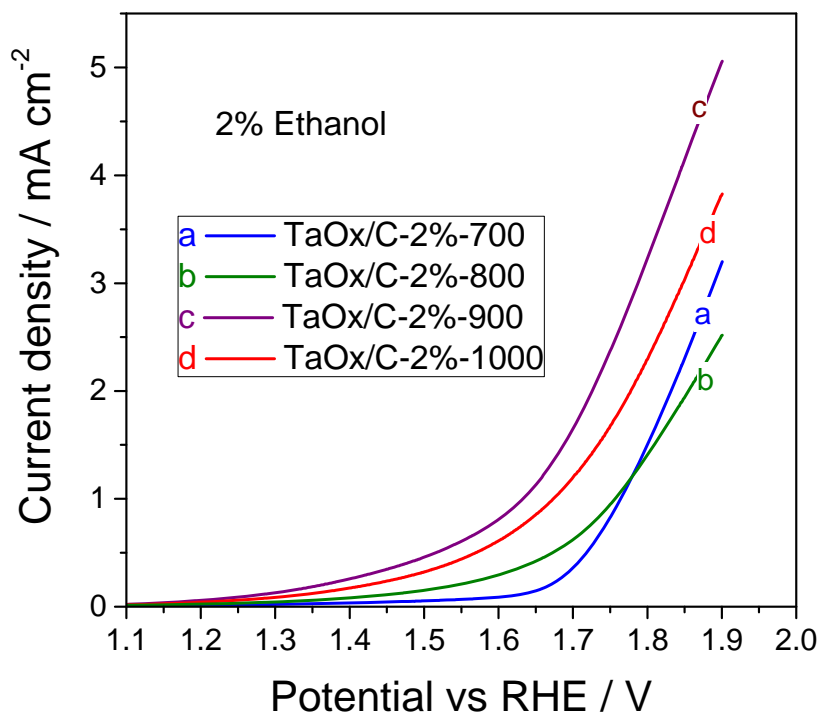

Figure 10. Effect of the annealing temperature on the OER polarization curves for the $2 \%$ ethanol catalyst. Linear sweep voltammetry at $5 \mathrm{mV} \mathrm{s}^{-1}, 1600 \mathrm{rpm}, 0.1 \mathrm{M} \mathrm{NaOH}, 45 \mu \mathrm{g} \mathrm{cm}^{-2}$ of Ta.

While at this stage the mechanism of OER catalysis remains unclear for the $\mathrm{TaOx} / \mathrm{C}$ catalyts, both the geometric and electronic factors can be mainly responsible for the improvement of catalytic activity at $900^{\circ} \mathrm{C}$. The exchange current density $\left(j_{0, O E R}\right)$ increases progressively with the annealing temperature. The most active OER catalysts are $\mathrm{TaOx} / \mathrm{C}-900$, with a Tafel slope approaching 300 $\mathrm{mV} \mathrm{dec}^{-1}$. This is not enough information to determine the rate determining step [31], not to mention the possible contribution from side reactions (e.g. carbon electro-oxidation), but clearly indicates faster kinetics in any case. The presence of $\mathrm{Na}_{2} \mathrm{Ta}_{8} \mathrm{O}_{21}$ crystal phase with higher crystallinity and preferential growth direction seems to favor the $\mathrm{OH}^{-}$oxidation towards oxygen. A further question involves conductivity, as the annealing temperature could affect the conductivity of the composites. It is reasonable to assume that the increased contact between crystals due to a collapse of the pores, upon high-temperature sintering, such as 900 and $1000^{\circ} \mathrm{C}$, can lead to an increase of the conductivity of the $\mathrm{TaOx} / \mathrm{C}$ catalysts. The lower activity of the catalysts annealed at $1000{ }^{\circ} \mathrm{C}$ compared to that at $900{ }^{\circ} \mathrm{C}$ is due to a decreasing dispersion of the active phase. Therefore, the $\mathrm{TaOx} / \mathrm{C}-2 \%$ and $\mathrm{TaOx} / \mathrm{C}-3 \%$ treated at $900^{\circ} \mathrm{C}$ catalysts exhibit a potential bifunctional electrochemical performance benefit from the synergistic catalytic effects towards ORR and OER processes. 


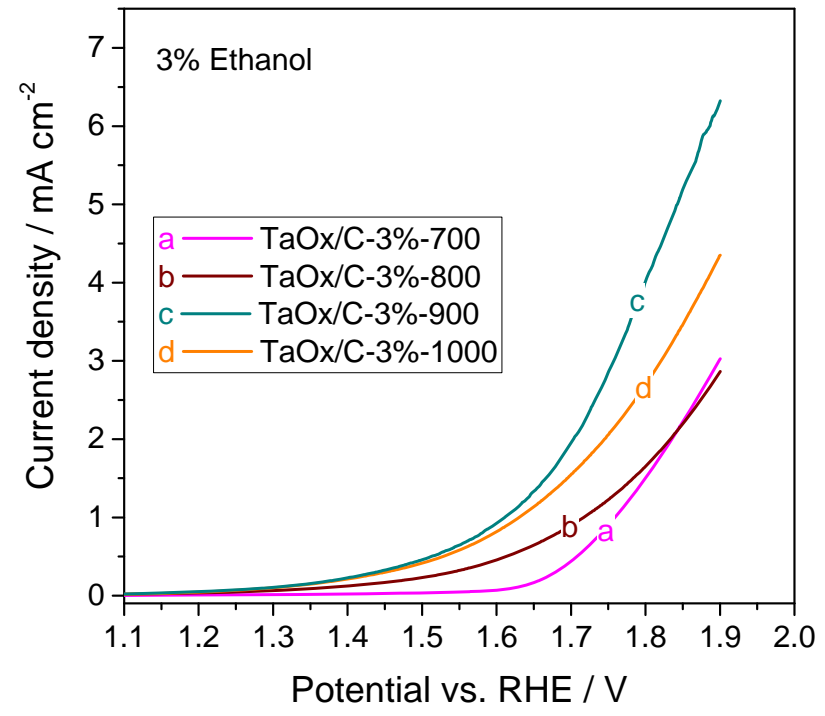

Figure 11. Effect of the annealing temperature on the OER polarization curves for the $3 \%$ ethanol catalyst. Linear sweep voltammetry at $5 \mathrm{mV} \mathrm{s}^{-1}, 1600 \mathrm{rpm}, 0.1 \mathrm{M} \mathrm{NaOH}, 45 \mu \mathrm{g} \mathrm{cm}^{-2}$ of Ta.

Table 6. Summary of OER electrokinetic parameters for catalysts synthesized by varying the ethanol concentration. jOER is the current density at $1.65 \mathrm{~V}$ vs. RHE, and $\mathrm{j}_{0, \mathrm{OER}}$ is the exchange current density (1.23 V vs. RHE).

\begin{tabular}{|l|c|c|c|}
\hline Electrocatalyst & $\begin{array}{c}\text { joer } \\
\left(\mathrm{mA} \mathrm{cm}^{-2}\right)\end{array}$ & $\begin{array}{c}\text { Tafel slope } \\
\left(\mathrm{mV} \mathrm{dec}^{-1}\right)\end{array}$ & $\begin{array}{c}\text { jo,OER } \\
\left(\mathrm{mA} \mathrm{cm}^{-2}\right)\end{array}$ \\
\hline TaOx/C-2\%-700 & 0.15 & 361 & $2.1 \cdot 10^{-2}$ \\
\hline TaOx/C-2\%-800 & 0.43 & 328 & $1.4 \cdot 10^{-2}$ \\
\hline TaOx/C-2\%-900 & 1.14 & 306 & $4.9 \cdot 10^{-2}$ \\
\hline TaOx/C-2\%-1000 & 0.86 & 341 & $5.0 \cdot 10^{-2}$ \\
\hline TaOx/C-3\%-700 & 0.17 & 290 & $1.9 \cdot 10^{-2}$ \\
\hline TaOx/C-3\%-800 & 0.65 & 329 & $3.5 \cdot 10^{-2}$ \\
\hline TaOx/C-3\%-900 & 1.37 & 304 & $6.2 \cdot 10^{-2}$ \\
\hline TaOx/C-3\%-1000 & 1.14 & 345 & $6.9 \cdot 10^{-2}$ \\
\hline
\end{tabular}

\subsubsection{Endurance tests}

Endurance tests were carried out in order to evaluate the electrode behavior with time under both ORR and OER conditions. Chronopotentiometric curves are shown in Figure 12 for the four tested catalysts (TaOx/C-2\%-900, TaOx/C-2\%-1000, TaOx/C-3\%-900 and TaOx/C-3\%-1000), selected as they exhibited the most performing behavior. Cut-off values of $1.9 \mathrm{~V}$ vs. RHE for the OER and of $0.2 \mathrm{~V}$ vs. RHE for the ORR were established. The number of cycles before reaching the OER cut-off potential was $15,13,16$ and 18 cycles for the catalysts $\mathrm{TaOx} / \mathrm{C}-2 \%-900, \mathrm{TaOx} / \mathrm{C}-2 \%$ 1000, $\mathrm{TaOx} / \mathrm{C}-3 \%-900$ and $\mathrm{TaOx} / \mathrm{C}-3 \%-1000$, respectively. The pseudo steady-state potential 
barely changes during the first 60 min of test for all the catalysts and for both oxygen evolution and reduction reactions. After a certain duration, there is a decrease of activity in both OER and ORR sides indicated by the variation of potential towards more positive values in OER and more negative values in ORR in the plot. The more pronounced variation of potential derives in reaching the upper cut-off value, and consequently the test is stopped. In view of the number of cycles, the catalyst prepared with $3 \%$ ethanol and annealed at $1000^{\circ} \mathrm{C}$ is the most resistant one. Interestingly, when the catalysts start losing activity with a higher degradation rate, the decay in performance in terms of larger overpotential is observed for both OER and ORR parts of the curves. This might indicate a similar nature for the active sites acting as catalytic centers for these two reactions (bifunctional sites).

a)
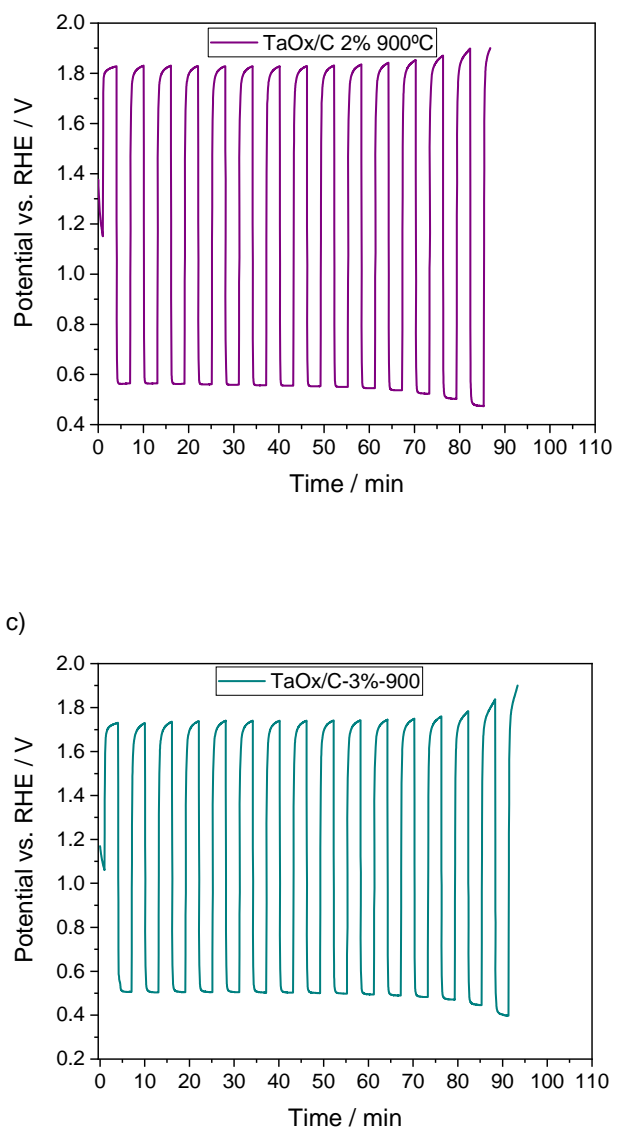

b)

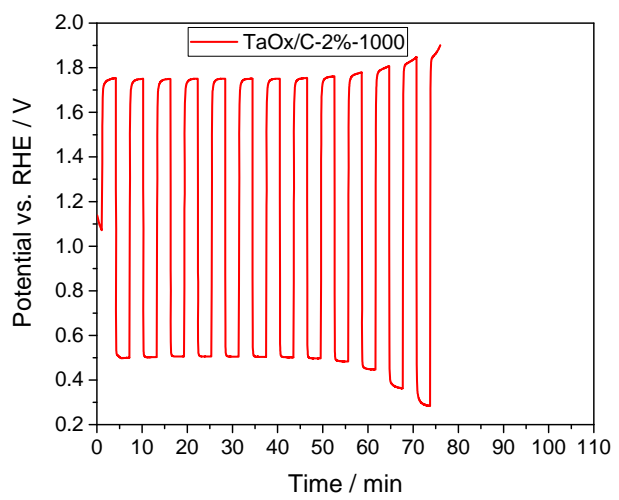

d)

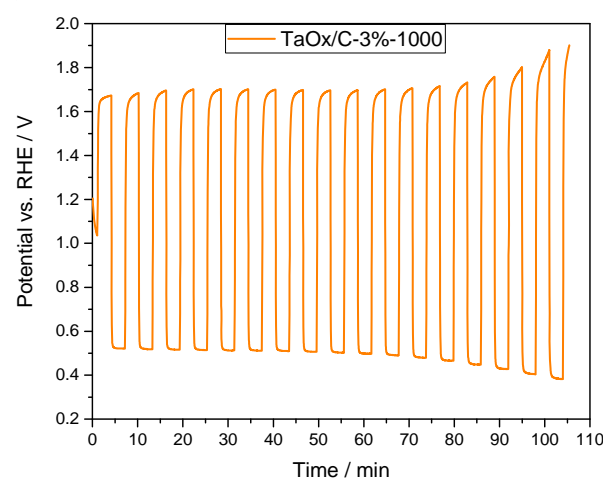

Figure 12. Chronopotentiometric cycles obtained for a) TaOx/C-2\%-900; b) TaOx/C-2\%-1000; c) TaOx/C-3\%-900; and d) TaOx/C-3\%-1000. 180 s/cycle at \pm 1 mA cm${ }^{-2}, \mathrm{O}_{2}$-saturated $0.1 \mathrm{M} \mathrm{NaOH}, 400$ rpm. 
ORR and OER polarization curves were recorded after the endurance tests. Table 7 shows the values of current density at the beginning and at the end of tests (BoT and EoT, respectively), together with the relative variation in percentage.

Table 7. Current density for the ORR ( $0.65 \mathrm{~V}$ vs. RHE) and the OER ( $1.65 \mathrm{~V}$ vs. RHE) by linear sweep voltammetry ( $5 \mathrm{mV} \mathrm{s}^{-1}, 1600 \mathrm{rpm}, 0.1 \mathrm{M} \mathrm{NaOH}, 45 \mu \mathrm{g} \mathrm{cm}^{-2}$ of Ta) at the beginning of test (BoT) and at the end of test (EoT) regarding the endurance experiments.

\begin{tabular}{|c|c|c|c|c|c|c|}
\hline & \multicolumn{3}{|c|}{ ORR } & \multicolumn{3}{|c|}{ OER } \\
\hline Electrocatalyst & $\begin{array}{c}\mathrm{j}_{\mathrm{k}, \mathrm{BoT}} \\
\left(\mathrm{mA} / \mathrm{cm}^{2}\right)\end{array}$ & $\begin{array}{c}\mathrm{j}_{\mathrm{k}, \text { EoT }} \\
\left(\mathrm{mA} / \mathrm{cm}^{2}\right)\end{array}$ & $\frac{\mathrm{j}_{\mathrm{k}, \text { EOT }}-\mathrm{j}_{\mathrm{k}, \mathrm{BOT} T}}{\mathrm{j}_{\mathrm{k}, \text { BoT }}}$ & $\begin{array}{c}\mathrm{j}_{\mathrm{BoT}} \\
\left(\mathrm{mA} / \mathrm{cm}^{2}\right)\end{array}$ & $\begin{array}{c}\mathrm{j}_{\mathrm{EoT}} \\
\left(\mathrm{mA} / \mathrm{cm}^{2}\right.\end{array}$ & $\frac{\mathrm{j}_{\mathrm{k}, \text { EOT }}-\mathrm{j}_{\mathrm{k}, \text { BoT }}}{\mathrm{j}_{\mathrm{k}, \text { BoT }}}$ \\
\hline TaOx/C-2\%-900 & -1.243 & -0.525 & $-58 \%$ & 1.135 & 1.023 & $-10 \%$ \\
\hline TaOx/C-2\%-1000 & -1.148 & -0.851 & $-26 \%$ & 0.857 & 0.442 & $-48 \%$ \\
\hline TaOx/C-3\%-900 & -1.239 & -1.230 & $-1 \%$ & 1.368 & 1.020 & $-25 \%$ \\
\hline $\mathrm{TaOx} / \mathrm{C}-3 \%-1000$ & -1.535 & -1.397 & $-9 \%$ & 1.139 & 0.140 & $-88 \%$ \\
\hline
\end{tabular}

Figure 13 shows a comparison of the OER and ORR voltammetric curves for the two catalysts with the largest activity, those annealed at $900^{\circ} \mathrm{C}$, including the curves after the endurance test (dashed lines). The end of test occurred for all the catalysts when reaching $1.9 \mathrm{~V}$ vs. RHE (overpotential of $0.67 \mathrm{~V}=1.9 \mathrm{~V}-1.23 \mathrm{~V}$, vs. RHE) at a demand of $1 \mathrm{~mA} \mathrm{~cm}^{-2}$. Table 7 indicates absolute current density values over $1 \mathrm{~mA} \mathrm{~cm}^{-2}$ at a lower overpotential for both OER $(0.42 \mathrm{~V}=$ $1.65 \mathrm{~V}-1.23 \mathrm{~V}$, vs. RHE) and ORR $(0.58 \mathrm{~V}=1.23 \mathrm{~V}-0.65 \mathrm{~V}$, vs. RHE) for some of the composites upon the endurance test. This points to a certain recovery of catalyst activity between the behavior exhibited in the endurance tests (chronopotentiometries of Figure 12) and the activity tests (linear sweep voltammetries of Figure 13). Further work is needed to individuate the causes for degradation in order to design synthesis strategies aimed to ameliorate these phenomena. 


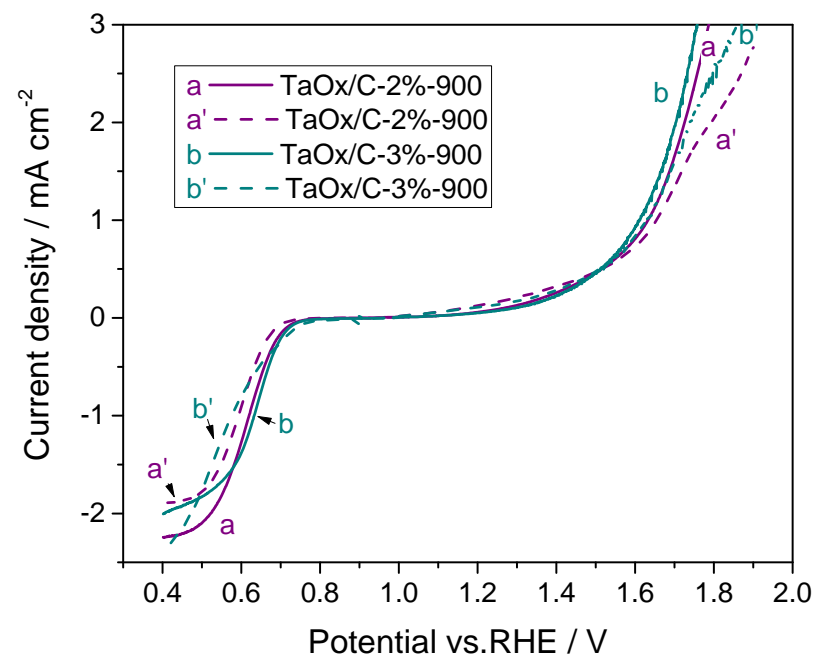

Figure 13. ORR and OER activity before (continuous line) and after (discontinuous line) the chronopotentiometric tests for the catalysts with the best electrocatalytic activity.

\section{Conclusions}

Carbon-supported tantalum-based catalysts were prepared by a microemulsion methodology from tantalum ethoxide precursor. The influence of ethanol concentration in the microemulsion (0-6 $\%)$ and the annealing temperature of the catalyst $\left(700-1000^{\circ} \mathrm{C}\right)$ were investigated. Metal oxide nanoparticles were formed by a mix of $\mathrm{Na}_{2} \mathrm{Ta}_{8} \mathrm{O}_{21}$ with other tantalum oxides and sodium tantalates. The specific composition relies mainly on ethanol concentration, as it influences the hydrolysis reaction. The thermal treatment at high temperature of these materials in the presence of carbon support (carbon black) conducts to oxygen contents below stoichiometric values, which is known to favor the electrochemical activity.

The activity of the catalysts towards ORR and OER in alkaline environment is favored by high crystallinity and the presence of sodium tantalate rather than tantalum oxide. Using intermediate ethanol concentration in the microemulsion and high annealing temperatures results in the best electroactivity for both ORR and OER, despite obtaining bigger crystallite sizes of Ta-based nanoparticles (40-50 nm) with lower surface area. Endurance tests based on chronopotentiometric analysis were performed to investigate the behavior at ORR and OER with time, suggesting that 
a part of the loss of activity observed during the endurance test can be recovered. Catalysts annealed at $900^{\circ} \mathrm{C}$ exhibited the most promising bifunctional behavior in terms of activity and durability. Further research is necessary to investigate the reaction mechanisms on the various Ta species, to individuate the nature of active sites and to determine the effect of the carbon support.

\section{Acknowledgements}

The authors wish to acknowledge the Ministerio de Ciencia, Innovación y Universidades (MICINN) and FEDER for the received funding in the project of reference ENE2017-83976-C21-R, as well as to the Gobierno de Aragón (DGA) for the funding to Grupo de Investigación Conversión de Combustibles (T06_17R). J.C. Ruiz-Cornejo acknowledges also DGA his PhD grant. D. Sebastián acknowledges also MICINN for his Ramón y Cajal research contract (RyC2016-20944).

\section{References}

[1] I. Katsounaros, S. Cherevko, A.R. Zeradjanin, K.J.J. Mayrhofer, Oxygen Electrochemistry as a Cornerstone for Sustainable Energy Conversion, Angewandte Chemie International Edition, 53 (2014) 102-121.

[2] Y. Wang, D.Y.C. Leung, J. Xuan, H. Wang, A review on unitized regenerative fuel cell technologies, part B: Unitized regenerative alkaline fuel cell, solid oxide fuel cell, and microfluidic fuel cell, Renewable and Sustainable Energy Reviews, 75 (2017) 775-795. [3] Z. Lijun, Z. Chunyan, C. Xiaoyi, Q. Yao, J. Haifeng, L. Baosheng, L. Linfei, S. Zexiang, H. Wei, N, P Co-doped Hierarchical Porous Graphene as a Metal-Free Bifunctional Air Cathode for Zn-Air Batteries, ChemElectroChem, 5 (2018) 1811-1816. 
[4] R.D. McKerracher, C. Alegre, V. Baglio, A.S. Aricò, C. Ponce de León, F. Mornaghini, M. Rodlert, F.C. Walsh, A nanostructured bifunctional Pd/C gas-diffusion electrode for metal-air batteries, Electrochimica Acta, 174 (2015) 508-515.

[5] C. Alegre, A. Stassi, E. Modica, C. Lo Vecchio, A.S. Aricò, V. Baglio, Investigation of the activity and stability of Pd-based catalysts towards the oxygen reduction (ORR) and evolution reactions (OER) in iron-air batteries, RSC Advances, 5 (2015) 25424-25427.

[6] R.D. McKerracher, H.A. Figueredo-Rodríguez, C. Ponce de León, C. Alegre, V. Baglio, A.S. Aricò, F.C. Walsh, A high-performance, bifunctional oxygen electrode catalysed with palladium and nickel-iron hexacyanoferrate, Electrochimica Acta, 206 (2016) 127-133.

[7] S. Altmann, T. Kaz, K.A. Friedrich, Bifunctional electrodes for unitised regenerative fuel cells, Electrochimica Acta, 56 (2011) 4287-4293.

[8] S. Zhao, L. Yan, H. Luo, W. Mustain, H. Xu, Recent progress and perspectives of bifunctional oxygen reduction/evolution catalyst development for regenerative anion exchange membrane fuel cells, Nano Energy, 47 (2018) 172-198.

[9] J.M. Luque-Centeno, M.V. Martínez-Huerta, D. Sebastián, G. Lemes, E. Pastor, M.J. Lázaro, Bifunctional N-doped graphene Ti and Co nanocomposites for the oxygen reduction and evolution reactions, Renewable Energy, 125 (2018) 182-192.

[10] X. Zhong, Y. Jiang, X. Chen, L. Wang, G. Zhuang, X. Li, J.-g. Wang, Integrating cobalt phosphide and cobalt nitride-embedded nitrogen-rich nanocarbons: high-performance bifunctional electrocatalysts for oxygen reduction and evolution, Journal of Materials Chemistry A, 4 (2016) 10575-10584.

[11] T. Pan, H. Liu, G. Ren, Y. Li, X. Lu, Y. Zhu, Metal-free porous nitrogen-doped carbon nanotubes for enhanced oxygen reduction and evolution reactions, Science Bulletin, 61 (2016) 889-896.

[12] Y. Fang, X. Li, F. Li, X. Lin, M. Tian, X. Long, X. An, Y. Fu, J. Jin, J. Ma, Self-assembly of cobalt-centered metal organic framework and multiwalled carbon nanotubes hybrids as a highly active and corrosion-resistant bifunctional oxygen catalyst, Journal of Power Sources, 326 (2016) 50-59. 
[13] Y. Tang, F. Jing, Z. Xu, F. Zhang, Y. Mai, D. Wu, Highly Crumpled Hybrids of Nitrogen/Sulfur Dual-Doped Graphene and Co9S8 Nanoplates as Efficient Bifunctional Oxygen Electrocatalysts, ACS Applied Materials \& Interfaces, 9 (2017) 12340-12347.

[14] H. Jiang, Y. Yao, Y. Zhu, Y. Liu, Y. Su, X. Yang, C. Li, Iron Carbide Nanoparticles Encapsulated in Mesoporous Fe-N-Doped Graphene-Like Carbon Hybrids as Efficient Bifunctional Oxygen Electrocatalysts, ACS Applied Materials \& Interfaces, 7 (2015) 2151121520.

[15] D. Sebastián, V. Baglio, S. Sun, A.C. Tavares, A.S. Aricò, Graphene-Supported Substoichiometric Sodium Tantalate as a Methanol-Tolerant, Non-Noble-Metal Catalyst for the Electroreduction of Oxygen, ChemCatChem, 7 (2015) 911-915.

[16] J. Seo, D. Cha, K. Takanabe, J. Kubota, K. Domen, Particle size dependence on oxygen reduction reaction activity of electrodeposited TaOx catalysts in acidic media, Physical Chemistry Chemical Physics, 16 (2014) 895-898.

[17] J. Seo, D.H. Anjum, K. Takanabe, J. Kubota, K. Domen, Electrodeposited Ultrafine TaOx/CB Catalysts for PEFC Cathode Application: Their Oxygen Reduction Reaction Kinetics, Electrochimica Acta, 149 (2014) 76-85.

[18] Z. Awaludin, T. Okajima, T. Ohsaka, Preparation of reduced tantalum pentoxide by electrochemical technique for oxygen reduction reaction, Journal of Power Sources, 268 (2014) $728-732$.

[19] J. Seo, L. Zhao, D. Cha, K. Takanabe, M. Katayama, J. Kubota, K. Domen, Highly Dispersed TaOx Nanoparticles Prepared by Electrodeposition as Oxygen Reduction Electrocatalysts for Polymer Electrolyte Fuel Cells, The Journal of Physical Chemistry C, (2013).

[20] J. Seo, D. Cha, K. Takanabe, J. Kubota, K. Domen, Electrodeposited Ultrafine NbOx, ZrOx, and TaOx Nanoparticles on Carbon Black Supports for Oxygen Reduction Electrocatalysts in Acidic Media, Acs Catalysis, 3 (2013) 2181-2189. 
[21] Z. Awaludin, M. Safuan, T. Okajima, T. Ohsaka, Investigating the physical and electrochemical effects of cathodic polarization treatment on TaOx, Journal of Materials Chemistry A, 3 (2015) 16791-16800.

[22] A. Ishihara, Y. Ohgi, K. Matsuzawa, S. Mitsushima, K.-i. Ota, Progress in non-precious metal oxide-based cathode for polymer electrolyte fuel cells, Electrochimica Acta, 55 (2010) 8005-8012.

[23] A. Ishihara, M. Tamura, K. Matsuzawa, S. Mitsushima, K.-i. Ota, Tantalum oxide-based compounds as new non-noble cathodes for polymer electrolyte fuel cell, Electrochimica Acta, $55(2010) 7581-7589$.

[24] Y. Ohgi, A. Ishihara, K. Matsuzawa, S. Mitsushima, K.-i. Ota, M. Matsumoto, H. Imai, Oxygen reduction reaction on tantalum oxide-based catalysts prepared from $\mathrm{TaC}$ and $\mathrm{TaN}$, Electrochimica Acta, 68 (2012) 192-197.

[25] A. Ishihara, S. Doi, S. Mitsushima, K.-i. Ota, Tantalum (oxy)nitrides prepared using reactive sputtering for new nonplatinum cathodes of polymer electrolyte fuel cell, Electrochimica Acta, 53 (2008) 5442-5450.

[26] D. Sebastián, V. Baglio, S. Sun, A.C. Tavares, A.S. Aricò, Facile synthesis of Zr- and Tabased catalysts for the oxygen reduction reaction, Chinese Journal of Catalysis, 36 (2015) 484489.

[27] H. Hajibabaei, T.W. Hamann, Selective Electrodeposition of Tantalum(V) Oxide Electrodes, Langmuir, 33 (2017) 10800-10806.

[28] A. Jo, Y. Lee, C. Lee, Electrodeposition of tantalum on carbon black in non-aqueous solution and its electrocatalytic properties, Analytica Chimica Acta, 933 (2016) 59-65. [29] M.H. Oh, N. Lee, H. Kim, S.P. Park, Y. Piao, J. Lee, S.W. Jun, W.K. Moon, S.H. Choi, T. Hyeon, Large-Scale Synthesis of Bioinert Tantalum Oxide Nanoparticles for X-ray Computed Tomography Imaging and Bimodal Image-Guided Sentinel Lymph Node Mapping, Journal of the American Chemical Society, 133 (2011) 5508-5515.

[30] H. Imai, M. Matsumoto, T. Miyazaki, S. Fujieda, A. Ishihara, M. Tamura, K.-i. Ota, Structural defects working as active oxygen-reduction sites in partially oxidized Ta-carbonitride 
core-shell particles probed by using surface-sensitive conversion-electron-yield x-ray absorption spectroscopy, 96 (2010) 191905.

[31] T. Shinagawa, A.T. Garcia-Esparza, K. Takanabe, Insight on Tafel slopes from a microkinetic analysis of aqueous electrocatalysis for energy conversion, Scientific Reports, 5 (2015) 13801.

[32] H. Shi, G. Zhao, Water Oxidation on Spinel NiCo2O4 Nanoneedles Anode:

Microstructures, Specific Surface Character, and the Enhanced Electrocatalytic Performance, The Journal of Physical Chemistry C, 118 (2014) 25939. 